Popular Summary of

\title{
Response of the Antarctic Stratosphere to two types of El Niño Events
}

submitted to Journal of the Atmospheric Sciences, July 2010

\author{
M.M. Hurwitz ${ }^{1}$, P.A. Newman 2, L.D. Oman ${ }^{2}$ and A.M. Molod \\ 3 \\ 1 NASA Postdoctoral Program, NASA Goddard Space flight Center, \\ Greenbelt, MD, USA \\ 2 NASA Goddard Space Flight Center, Greenbelt, MD, USA \\ 3 Goddard Earth Sciences and Technology Center, University of Maryland, \\ Baltimore County, Baltimore, MD, USA
}

Conventional El Niño events are characterized by warmer than average sea surface temperatures in the equatorial eastern Pacific Ocean and by an eastward shift in atmospheric convection from Asia toward the central Pacific. The largest El Niño event in recent decades occurred in 1997/1998. The El Niño signal propagates polewards and upwards as largescale atmospheric waves, leading to unusual weather worldwide and changing conditions in the stratosphere. While the Arctic stratosphere warms in response to these conventional or "cold tongue" type of El Niño events, the Antarctic stratosphere is unaffected.

Recently, a second type of El Niño event has been identified. During "warm pool" El Niño events, sea surface temperatures in the central Pacific are warmer than average. This study identifies a robust warming of the Antarctic stratosphere in Southern Hemisphere spring and summer, in response to "warm pool" El Niño events, using atmospheric data from 1979 to 2009. The Antarctic warming associated with "warm pool" El Niño events is most pronounced when these events are coincident with westward winds in the tropical lower and middle stratosphere. Westward winds may enhance wave activity in the subtropical troposphere and/or push wave energy toward polar latitudes. Because of the small number of observed El Niño events, model experiments will be required to better understand how tropical winds affect the Antarctic response to "warm pool" El Niño events. 
M. M. Hurwitz et al. (2010)

El Niño Response in the Antarctic Stratosphere

1 Response of the Antarctic Stratosphere 2 to two types of El Niño Events

3

4 M. M. Hurwitz ${ }^{1}$, P. A. Newman 2, L. D. Oman 2 and A. 5 M. Molod 3

61 NASA Postdoctoral Program, NASA Goddard Space Flight Center, 7 Greenbelt, MD, USA

82 NASA Goddard Space Flight Center, Greenbelt, MD, USA

93 Goddard Earth Sciences and Technology Center, University of Maryland, Baltimore County, Baltimore, MD, USA

12 Corresponding author information

13 Email address: margaret.m.hurwitz@nasa.gov

14 Mailing address: NASA Goddard Space Flight Center Code 613.3 Greenbelt, MD USA 20771 
Abstract

20 This study is the first to identify a robust El Niño/Southern

21 Oscillation (ENSO) signal in the Antarctic stratosphere. El Niño

22 events are classified as either conventional "cold tongue" events 23 (positive SST anomalies in the Niño 3 region) or "warm pool" 24 events (positive SST anomalies in the Niño 4 region). The ERA2540 , NCEP and MERRA meteorological reanalyses are used to show 26 that the Southern Hemisphere stratosphere responds differently to 27 these two types of El Niño events. Consistent with previous 28 studies, "cold tongue" events do not impact temperatures in the 29 Antarctic stratosphere. During "warm pool" El Niño events, the 30 poleward extension and increased strength of the South Pacific 31 Convergence Zone (SPCZ) favor an enhancement of planetary wave 32 activity during the SON season. On average, these conditions 33 lead to higher polar stratospheric temperatures and a weakening 34 of the Antarctic polar jet in November and December, as compared 35 with neutral ENSO years. The phase of the quasi-biennial 36 oscillation (QBO) modulates the stratospheric response to "warm 37 pool" El Niño events: the strongest planetary wave driving 38 events are coincident with the easterly phase of the QBO. 
El Niño Response in the Antarctic Stratosphere

\section{Introduction}

41 El Niño/Southern Oscillation (ENSO) has a stratospheric signature in both the tropics and in the Arctic. In the tropics, the lower stratospheric temperature response to ENSO has the opposite sign as that in the troposphere, i.e. a cooling associated with ENSO warm phase (El Niño) events (Calvo Fernandez et al., 2004; Garcia-Herrera et al., 2006; Free and Seidel, 2009). This tropical lower stratospheric cooling reflects the strengthening of the upwelling branch of the Hadley cell.

Using both observations and a chemistry-climate model (CCM), Randel et al. (2009) showed that increased tropical upwelling during El Niño events leads to temperature.

El Niño events have been shown to weaken the Northern Hemisphere El Niño-related warming of the Arctic stratosphere has been identified in observational (Bronnimann et al., 2004; Free and Seidel, 2009) and modeling studies (Sassi et al., 2004; Manzini et al., 2006; Cagnazzo et al., 2009). Warming of the Arctic stratosphere is a response to increased planetary wave

60 driving: Garfinkel and Hartmann (2008) showed that the

61 extratropical tropospheric teleconnections produced during $E l$ 62 Niño events weaken the Arctic vortex, leading to higher 63 stratospheric temperatures during the $\mathrm{NH}$ winter season. The 64 phase of the quasi-biennial oscillation (QBO) (Garfinkel and 65 Hartmann, 2007; Bronnimann, 2007) and volcanic activity (Randel 66 et al., 2009) modulate this response. The Arctic vortex is 67 weakest in years when El Niño events coincide with the easterly 68 phase of the QBO (Garfinkel and Hartmann, 2007). 
70 Previous studies of the stratospheric response to ENSO have 71 considered a single type of El Niño event. The sea surface 72 temperature (SST) anomaly pattern associated with these events, a band of positive SST anomalies spanning the eastern Pacific, was identified by Rasmusson and Carpenter (1982) and was termed a “cold tongue" El Niño event (hereafter CT El Niño) by Kug et al. (2009). The SST and precipitation anomalies associated with CT El Niño events develop during the June-July-August (JJA) and September-October-November (SON) seasons, peak in DecemberJanuary-February (DJF), and decay in the March-April-May (MAM) season. The multivariate ENSO index (MEI ; WWw.esrl.noaa.gov/psd/people/klaus.wolter/MEI), Niño 3 and Niño 3.4 indices (WWW.cpc.noaa.gov/data/indices) capture this leading mode of variability in the tropical Pacific (Calvo Fernandez et al., 2004; Ashok et al., 2007) and maximize during CT El Niño events, when SST anomalies and convective activity in the eastern equatorial Pacific are unusually high. The two largest CT El Niño events of the satellite era occurred in 1982/1983 and

Recent literature recognizes a second type of El Niño event. These events have been referred to as "dateline El Niño" (Larkin and Harrison, 2005), "El Nino Modoki” (Ashok et al., 2007) and “warm pool El Niño" (Kug et al., 2009) (hereafter WP El Niño). WP El Niño events capture the secondary mode of variability in tropical Pacific SSTS: positive SST anomalies in the tropical central Pacific, and negative SST anomalies in the western and eastern tropical Pacific (Ashok et al., 2007). SST and precipitation anomalies maximize in the SON and DJF seasons (Kug et al., 2009; $\mathrm{Yu}$ and $\mathrm{Kim}, 2010)$ 
102 The two types of El Niño events can be distinguished not only by 103 the region in which SST anomalies are greatest, but also by the 104 relative position and strength of the South Pacific Convergence 105 Zone (SPCZ). Vera et al. (2004) found that the extratropical 106 component of the SPCZ is stronger and extends further south in WP 107 El Niño-like events as compared with either CT El Niño-like or 108 ENSO neutral events. The same authors found relative increase in 109 planetary wave activity in the south central Pacific in response 110 to all El Niño events, and furthermore, identified a Rossby wave 111 source centered at approximately $20^{\circ} \mathrm{S}, 240^{\circ} \mathrm{E}$ in $\mathrm{El}$ Niño events 112 with enhanced SPCZ activity (WP El Niño-like) relative to El Niño 113 events with suppressed SPCZ activity (CT El Niño-like).

114

115 While the planetary wave response to CT El Niño modulates 116 conditions in the Arctic stratosphere (Garfinkel and Hartmann, 117 2008), this paper shows that an analogous enhancement in wave 118 activity during WP El Niño events affects conditions in the 119 Antarctic stratosphere. In particular, differences between the 120 SH wave response to WP El Niño and CT El Niño may explain much of 121 the interannual variability in the strength of the Antarctic 122 vortex. In Section 2, atmospheric datasets are defined and El 123 Niño events are categorized. In section 3, tropospheric 124 stationary wave patterns, eddy heat flux, stratospheric 125 temperature and winds are used to illustrate the atmospheric 126 response to El Niño events, as well as the modulation of this 127 response by the QBO. Section 4 provides a summary of the results 128 and a brief discussion.

129

1302 Methods

1312.1 Identification of EL Niño events and QBO phase 
132 In this study, El Niño events are identified using two climate 133 indices. The Niño 3 index (WWW.cpc.noaa.gov/data/indices) 134 measures SST anomalies in the eastern equatorial Pacific Ocean 135 (the Niño 3 region; $5^{\circ} \mathrm{S}-5^{\circ} \mathrm{N}, \quad 210-270^{\circ} \mathrm{E}$ ). The Niño 4 index 136 measures SST anomalies in the central equatorial Pacific (the 137 Niño 4 region; $\left.5^{\circ} \mathrm{S}-5^{\circ} \mathrm{N}, 160-210^{\circ} \mathrm{E}\right)$. In this study, WP El Niño 138 events are identified when SON seasonal mean Nino 4 anomalies 139 exceed one standard deviation from the 1971-2000 mean (Figure 1 , 140 top panel). CT El Niño events are identified when SON mean Niño 1413 anomalies exceed one standard deviation from the 1971-2000 142 mean, and, are larger than the corresponding Niño 4 anomalies 143 (Figure 1, second panel). Note that WP El Niño events appear as 144 secondary peaks in the Niño 3 timeseries. Note also that the 145 Niño 3 standard deviation is larger than the Niño 4 standard 146 deviation; that is, the magnitudes of the positive SST anomalies 147 that define a WP El Niño event are smaller than those that define 148 a CT El Niño event. Neutral ENSO years are defined as those when 149 the SON and DJF mean Niño 3 and Niño 4 indices are both between $150 \quad 0.7$ and 0.7 . Table 1 specifies years in which the above criteria 151 are met. Kug et al. (2009) used the SONDJF seasonal mean to 152 select a slightly different set of WP and CT El Niño events; 153 also, the authors defined a "mixed" type of El Niño event in 154 which the maximum area of SST anomalies is located between the 155 Niño 3 and Niño 4 regions.

157 A third index characterizes the phase of the quasi-biennial 158 oscillation (QBO). Following Garfinkel and Hartmann (2008), this 159 index is calculated by averaging $50 \mathrm{hPa}$ zonal winds between $10^{\circ} \mathrm{S}$ 160 and $10^{\circ} \mathrm{N}$ from November through February (i.e., the austral summer 161 season following each SON season). QBO easterly years (QBO-E) 162 are defined when the QBO index is larger than $3.3 \mathrm{~m} \mathrm{~s}^{-1}$ and QBO 
163 westerly years (QBO-W) are defined when the QBO index is less

164 than $-3.3 \mathrm{~m} \mathrm{~s}^{-1}$ (Figure 1, third panel). Easterly QBO years are 165 denoted with star symbols in Table 1; years when WP El Niño 166 coincides with the easterly phase of the QBO are denoted as thick 167 blue stars in Figure 1 (third panel).

\subsection{Atmospheric Datasets}

170 Various atmospheric datasets are used to assess the atmospheric 171 response to the two types of $E l$ Niño events as defined in Section 172 2.1. Monthly mean precipitation is taken from the Global 173 Precipitation Climatology Project (GPCP) merged precipitation 174 dataset, version 2.1 (Adler et al., 2003; Bolvin et al., 2009). 175 Data are available from 1979 through 2007 , with $2.5^{\circ} \times 2.5^{\circ}$ 176 horizontal resolution. Three meteorological reanalyses are used 177 to calculate streamfunction, heat flux, temperature and zonal 178 wind diagnostics. Given the small number of observed El Niño 179 events since 1979, similarities in the El Niño response between 180. two or more reanalysis datasets will increase the robustness of 181 the results. Also, multiple reanalyses will test the sensitivity 182 of the results to the number and type of events included in the 183 analysis.

185 The European Centre for Medium-Range Weather Forecasts' 40-year 186 meteorological reanalysis (ERA-40) (Uppala et al., 2005) has 187 vertical coverage up to $1 \mathrm{hPa}$, and for this study, is 188 interpolated to a $2.5^{\circ} \times 2.5^{\circ}$ horizontal grid. The 1979-2001 189 period is used in this analysis.

190

191 The Modern Era Retrospective-Analysis for Research and 192 Applications (MERRA) is a reanalysis dataset based on an 193 extensive set of satellite observations and on the Goddard Earth 
194 Observing System Data Analysis System, Version 5 (GEOS-5) 195 (Bosilovich et al., 2008). Currently, the MERRA reanalysis 196 extends from 1979 through 2009. The MERRA reanalysis has 197 vertical coverage up to $0.1 \mathrm{hPa}$, and for this study, $1.25^{\circ} \mathrm{x}$ $1981.25^{\circ}$ horizontal resolution.

200 The National Centers for Environmental Prediction-US Department 201 of Energy (NCEP-DOE) reanalysis-2 product (Kanamitsu et al., 202 2002) covers the period from 1979 through 2009. The NCEP 203 reanalysis has $2.5^{\circ} \times 2.5^{\circ}$ horizontal resolution and vertical 204 coverage up to $10 \mathrm{hPa}$.

2063 Results

2073.1 Southern Hemisphere response to WP El Niño and CT El 208 Niño events

209 In this section, observed precipitation, horizontal winds, eddy 210 heat flux and temperature fields are used to show that the 211 strength and position of the SPCZ controls the SH stratospheric 212 response to El Niño events.

214 The strength and position of the SPCZ are largely controlled by 215 the phase of ENSO (Juillet-Leclerc et al., 2006), and 216 furthermore, by the type of $E l$ Niño event. Figure 2 shows GPCP 217 precipitation differences, in WP El Niño and CT El Niño events 218 relative to an ENSO neutral composite, in the SPCZ region. There 219 is more precipitation associated with the SPCZ, which extends 220 diagonally from the northwest to the southeast corner of each 221 plot, during both types of El Niño events than in ENSO neutral 222 years. In WP El Niño events (Figure $2 a$ ), there is a coherent 223 increase in precipitation of $0.5-1 \mathrm{~mm} \mathrm{day}^{-1}$ at the southeastern 224 edge of the SPCZ. This region of increased precipitation 
225 coincides with the location of the largest correlations between 226 precipitation and October/November mid-latitude heat flux at 100 $227 \mathrm{hPa}$ (Figure 3).

229 El Niño events trigger a planetary wave response in the SH. Vera 230 et al. (2004) found that the intensification and southeastward 231 extension of SPCZ activity strengthened the local overturning 232 circulation, leading to a relative Rossby wave source in the 233 south central Pacific in WP-like as compared with CT-like El Niño 234 events. This analysis will reproduce the results of vera et al. 235 (2004) using WP and CT El Niño events, as defined in Section 2.1. 236 In Figure $4,250 \mathrm{hPa}$ SON streamfunction differences from an ENSO 237 neutral composite illustrate the planetary wave responses to both 238 types of El Niño events. Each panel of Figure 4 shows a 239 wavetrain response to El Niño: Negative streamfunction 240 differences in the subtropics, close to the dateline (region 241 denoted by $A$ in Figure $4 C$ ), positive streamfunction differences 242 at mid-latitudes (region $B$ ), and negative streamfunction 243 differences around $240^{\circ} \mathrm{E}, 60^{\circ} \mathrm{S}$ (region $\mathrm{C}$ ). The red arrows in 244 Figures $4 a$ and $4 b$ indicate the approximate propagation direction 245 of the wavetrains. The region $A$ and $B$ differences are 246 statistically significant in both types of $E l$ Nino events, and in 247 all three reanalyses. Region $C$ differences are statistically 248 significant in the case of WP El Niño (Figures $4 a, 4 c$ and $4 e$ ) but 249 are not statistically significant in CT El Niño (Figures 4b, 4d 250 and $4 \mathrm{f}$ ). The fourth panel in Figure 1 shows a timeseries of 250 $251 \mathrm{hPa}$ streamfunction in region $\mathrm{C}$; note that the lowest values are 252 concurrent with WP El Niño events. This evidence suggests that 253 there is a stronger planetary wave response to WP El Niño events 254 than to CT El Niño events, consistent with vera et al. (2004). 
256 Eddy heat flux is used to quantify the amount of planetary wave 257 energy entering the stratosphere during El Niño and ENSO neutral 258 events. Eddy heat flux ( $\overline{v^{\prime} T}$ ) at $100 \mathrm{hPa}$, averaged between $40^{\circ} \mathrm{S}$ 259 and $80^{\circ} \mathrm{S}$, has been used to diagnose planetary wave driving in 260 chemistry-climate model validation studies. (Austin et al., 2003; 261 Eyring et al., 2006). October/November eddy heat flux at $100 \mathrm{hPa}$ 262 will be the focus of this study, as previous work has shown that 263 it plays an important role in the timing of the breakup of the 264 Antarctic vortex (Hurwitz et al., 2010). Table 2 shows the mean 265 eddy heat flux magnitudes in each of the ENSO cases, and for each 266 of the reanalyses. For the MERRA and NCEP reanalyses, mean eddy 267 heat flux is shown both for the ERA-40 period (1979-2001) and for 268 1979-2009. Eddy heat flux values are broadly consistent amongst 269 the three reanalyses (see also Figure 1, fifth panel) and are not 270 sensitive to the length of the timeseries used in the analysis. 271 Note, however, that eddy heat flux is largest in the WP El Niño 272 cases, and furthermore, larger in the 1979-2001 period as 273 compared with the 1979-2009 period. Variability among WP El Niño 274 events is roughly twice as large as that between CT El Niño and 275 ENSO neutral events (see discussion in Section 3.2).

277 Newman et al. (2001) identified a positive relationship between 278 mid-latitude eddy heat flux at $100 \mathrm{hPa}$ and polar temperatures at $27950 \mathrm{hPa}$, with a roughly one-month lag. Given the relatively 280 larger October/November eddy heat flux values in WP El Niño 281 events as compared with CT El Niño and ENSO neutral events (Table 282 2), the November/December stratospheric temperature response to 283 WP El Niño events would be expected to be larger from that of CT 284 El Niño events. Figure 5 shows mean November/December 285 temperature differences in the WP EL Niño and CT El Niño 286 composites, as compared with neutral ENSO years. At polar 
287 latitudes, WP El Niño events (Figures $5 \mathrm{a}, 5 \mathrm{C}$ and $5 \mathrm{e}$ ) warm the 288 tropical upper troposphere and lower stratosphere and cool the 289 upper stratosphere. The lower stratospheric warming response is 290 statistically significant in ERA-40 (3-5 K) but not in MERRA or 291 NCEP. The upper stratospheric cooling (1-2 K in MERRA; see 292 Figure 5C) is a wave filtering effect (Hurwitz et al., 2010): in 293 WP El Niño events, heat flux is higher and the Antarctic vortex 294 breaks up earlier. Summertime easterly winds do not allow 295 planetary wave propagation, leading to lower temperatures. 296 During CT El Nino events (Figures $5 b, 5 d$ and $5 f$ ), consistent with 297 previous observational studies (Free and Seidel, 2009; Randel et 298 al., 2009), none of the reanalyses show a statistically 299 significant temperature response in the Antarctic lower 300 stratosphere.

\subsection{QBO influence on the response to WP El Niño events}

303 The response of the Antarctic stratosphere to WP El Niño events 304 is systematically different from that to CT El Niño events. 305 However, the relative increases in heat flux and polar lower 306 stratospheric temperatures during WP El Niño events are not 307 statistically different from ENSO neutral events. The high 308 degree of variability amongst WP EL Niño events may be related to 309 the phase of the QBO.

311 In the Arctic lower stratosphere, the largest warming response to 312 CT El Niño is seen in years when the phase of the QBO is easterly 313 (Calvo Fernandez et al., 2004; Manzini et al., 2006). The 314 Antarctic lower stratosphere responds analogously. Of WP El Niño 315 events, eddy heat flux is larger in years when the QBO is 316 easterly than in years when winds are either weak or westerly 317 (Table 3); differences between the two QBO groupings are 
318 significant at the $95 \%$ level in all three reanalyses.

319 Conversely, in ENSO neutral years, the QBO phase makes no 320 difference to the magnitude of the October/November eddy heat 321 flux. The sensitivity of CT El Niño events to QBO phase cannot 322 be assessed, as all three observed CT El Niño events coincide 323 with weak equatorial zonal winds at $50 \mathrm{hPa}$.

325 The NCEP reanalysis is used to examine the temperature response 326 to WP El Niño events, as a function of QBO phase, as its 327 timeseries are long enough to sample of each of the QBO and ENSO 328 cases. The MERRA reanalysis yields very similar results. 329 Figures $6 \mathrm{a}$ and $6 \mathrm{~b}$ show temperature differences between WP El Niño 330 events, partitioned by QBO phase, and the ENSO neutral composite. 331 At high latitudes, a warming of $3-5 \mathrm{~K}$ is seen in easterly QBO 332 years (Figure 6a) whereas there is no significant warming in 333 years when the QBO is either neutral or westerly (Figure 6b).

335 In the Antarctic stratosphere, the zonal wind response to El Niño 336 events is consistent with the temperature response. The relative 337 warming of the lower Antarctic stratosphere during WP El Niño 338 events reduces the meridional temperature gradient, and by the 339 thermal wind balance, weakens the polar jet. The largest wind 340 differences from the ENSO neutral composite are seen in WP El 341 Niño events coincident with QBO-E (note the easterly winds at 50 $342 \mathrm{hPa}$ at the equator in Figure 6C). In the NCEP reanalysis, there 343 are statistically significant negative zonal wind differences of 344 up to $7 \mathrm{~m} \mathrm{~s} \mathrm{~s}^{-1}$ in the lower and middle stratosphere at 345 approximately $60^{\circ} \mathrm{S}$ (Figure 6C). This jet weakening is 346 approximately twice as large as that seen in the WACCM model in 347 the Arctic stratosphere in January (Taguchi, 2010), in ENSO warm 348 phase as compared with cold phase events. Consistent with the 
349 negligible temperature differences seen in Figure 5 , the 350 Antarctic jet does not weaken in response to CT El Niño events,

3524 Summary and Discussion

353 This study examined the response of the Antarctic stratosphere to 354 two types of El Niño events: warm pool (WP) El Niño and cold 355 tongue (CT) El Niño. WP El Niño events are characterized by 356 positive SST anomalies in the equatorial central Pacific (i.e., 357 the Niño 4 region) during austral spring and summer. This 358 analysis found that the Niño 4 index is a better indicator of the 359 SH dynamical response to El Niño than are indices that favor the 360 eastern Pacific. The Niño 3, Niño 3.4 and MEI indices have been 361 used in previous studies to identify the stratospheric signature 362 of CT El Niño events in the tropics and in the Arctic; however, 363 these indices have failed to identify an El Niño response in the 364 Antarctic stratosphere. Thus, evaluation of the global impact of 365 ENSO on the stratosphere requires measures of SST changes in both 366 the eastern (Niño 3) and central equatorial Pacific (Niño 4) 367 regions.

369 The strength and poleward extension of the SPCZ during the SON 370 season largely determine the SH stratospheric response to ENSO. 371 While SPCZ activity increases during both types of El Niño 372 events, precipitation is significantly enhanced in the 373 southeastern part of the SPCZ during WP El Niño events. Both 374 types of El Niño events generated a planetary wave response in 375 the SH troposphere, but again, this wave response extended 376 further poleward during WP El Niño events than during CT El Niño 377 events. As a result, SH planetary wave driving in October and 378 November (specifically, mid- to high latitude heat flux at 100 
379 hPa) was stronger during WP El Niño events, compared with both CT 380 El Niño events and ENSO neutral years.

382 During WP El Niño events, enhanced planetary wave activity warmed 383 the Antarctic upper troposphere and lower stratosphere and 384 weakened the stratospheric polar jet. The Antarctic response to 385 WP El Niño appears to be modulated by the phase of the QBO: a 3-5 386 K warming was seen in QBO easterly phase events whereas there was 387 no significant warming in years with a weak or westerly QBO. 388 Following the Holton and Tan (1980) mechanism, the easterly phase 389 of the QBO may confine lower stratospheric planetary wave390 breaking to middle and high latitudes, weakening the Antarctic 391 vortex. However, during WP El Niño events, the strength of the 392 SPCZ is highly dependent on the phase of the QBO, suggesting that 393 a tropical mechanism may be involved. Collimore et al. (2003) 394 argue that the phase of the QBO modulates the tropopause height 395 and thus the height of deep convection in the tropics. These 396 authors found a strengthening of convective activity in the SPCZ 397 region during austral spring, in QBO-E relative to QBO-W years, 398 possibly explaining the QBO modulation of the SH stratospheric 399 response to WP El Niño events. Compared with the 2-4 K warming 400 of the Arctic lower stratosphere during CT El Niño events, as 401 found by Free and Seidel (2009), the warming of the Antarctic 402 lower stratosphere during WP El Niño events was comparable during 403 easterly QBO years but weaker on average. Coupled ocean404 atmosphere model simulations predict that the pattern of SST 405 trends will favor WP El Niño events in future (Yeh et al., 2009; 406 Xie et al., 2010); thus, ENSO-related warming of the Antarctic 407 lower stratosphere may offset some of the direct radiative 408 cooling by greenhouse gases. 
410 While WP El Niño events have a significant impact on temperature, 411 they have a negligible impact on polar ozone. WP El Niño events 412 reach maturity in austral spring and summer (Kug et al., 2009), 413 after the formation of the ozone hole. Compared with ENSO 414 neutral years, ozone differences in the Antarctic lower 415 stratosphere were negligible in both WP El Niño and CT El Niño 416 events.

418 The ERA-40, MERRA and NCEP reanalyses were in agreement when the 419 same time periods were compared. That is, the different 420 horizontal and vertical resolutions of the three reanalysis 421 datasets did not affect the results. However, the stratospheric 422 response to WP El Niño events was dependent on the time period 423 analyzed: the WP El Niño events after 2001 mainly occurred in 424 westerly or neutral QBO years, reducing the e.g., mean 425 temperature response to WP EL Niño events in MERRA and NCEP 426 (1979-2009) as compared with ERA-40 (1979-2001).

428 One shortcoming of using meteorological reanalyses to diagnose 429 the stratospheric response to $E l$ Niño events is the small number 430 of such events that occurred between 1979 and 2009 . The 431 statistical significance of the results was lacking in some cases 432 (i.e., the temperature response to WP El Niño events in the MERRA 433 and NCEP reanalyses). Time-slice simulations, with repeating El 434 Niño-like boundary conditions, would greatly increase the sample 435 size and better separate the WP El Niño and CT El Niño signals 436 from the variability between events of the same type. 
M. M. Hurwitz et al. (2010)

El Niño Response in the Antarctic Stratosphere

439 MMH is supported by an appointment to the NASA Postdoctoral 440 Program at Goddard Space Flight Center, administered by Oak Ridge 441 Associated Universities through a contract with NASA. 


\section{References}

443 Adler, R. F., and Coauthors, 2003: The version-2 global 444 precipitation climatology project (GPCP) monthly precipitation 445 analysis (1979-present). J. Hydrometeorol., 4, 1147-1167.

447 Ashok, K., S. K. Behera, S. A. Rao, H. Weng, and T. Yamagata, 448 2007: El Niño Modoki and its possible teleconnections. J. 449 Geophys. Res., 112, C11007, doi:10.1029/2006JC003798.

451 Austin, J., and Coauthors, 2003: Uncertainties and assessments 452 of chemistry-climate models of the stratosphere. Atmos. Chem. 453 Phys., 3, 1-27.

455 Bolvin, D. T., R. F. Adler, G. J. Huffman, E. J. Nelkin and J. P. 456 Poutiainen, 2009: Comparison of GPCP monthly and daily 457 precipitation estimates with high-latitude gauge observations. 458 J. Appl. Meteor. Climatol., 48, 1843-1857.

459

460 Bronnimann, S., 2007: The impact of El Niño-Southern Oscillation 461 on European climate. Rev. Geophys., 45, RG3003, 462 doi:10.1029/2006RG000199.

463

464 Bronnimann, S., J. Luterbacher, J. Staehelin, T. M. Svendby, G. 465 Hansen, and T. Svene, 2004: Extreme climate of the global 466 troposphere and stratosphere in 1940-42 related to El Niño. 467 Nature, 431, 971-974, doi:10.1038/nature02982.

469 Bosilovich, M., 2008: NASA'S modern era retrospective-analysis 470 for research and applications: integrating earth observations. 471 Earthzine, Sep. 26. 
473 Cagnazzo, C., and Coauthors, 2009: Northern winter stratospheric 474 temperature and ozone response to ENSO inferred from an ensemble 475 of Chemistry Climate Models. Atmos. Chem. Phys., 9, 8935-8948.

477 Calvo Fernandez, N., R. R. Garcia, R. Garcia Herrera, D. Gallego 478 Puyol, L. Gimeno Presa, E. Hernandez Martin, and P. Ribera 479 Rodriguez, 2004: Analysis of the ENSO signal in tropospheric and 480 stratospheric temperatures observed by MSU, 1979 - $2000 . \mathrm{J}$. 481 Climate, $17, \quad 3934-3946, \quad$ doi:10.1175/1520$482 \quad 0442(2004) \Theta 17<3934:$ AOTESI $>2.0 . C 0 ; 2$.

484 Collimore, C. C., D. W. Martin, M. H. Hitchman, A. Huesman and D. 485 E. Waliser, 2003: On the relationship between the QBO and 486 tropical deep convection. J. Climate, 16, 2552-2568.

488 Eyring, V., and Coauthors, 2006: Assessment of temperature, 489 trace species and ozone in chemistry-climate model simulations of 490 the recent past. J. Geophys. Res., 111, D22308, 491 doi:10.1029/2006JDO07327.

492

493 Free, M., and D. J. Seidel, 2009: Observed El Niño-Southern 494 Oscillation temperature signal in the stratosphere. J. Geophys. 495 Res., 114 , D23108, doi:/10.1029/2009JD012420.

497 Garcia-Herrera, R., N. Calvo, R. R. Garcia, and M. A. Giorgetta, 498 2006: Propagation of ENSO temperature signals into the middle 499 atmosphere: A comparison of two general circulation models and 500 ERA-40 reanalysis data. J. Geophys. Res., 111, D06101, 501 doi:10.1029/2005JD006061. 
503 Garfinkel, C. I., and D. L. Hartmann, 2007: Effects of the El 504 Niño-Southern Oscillation and the Quasi-Biennial Oscillation on 505 polar temperatures in the stratosphere. J. Geophys. Res., 112 , 506 D19112, doi:10.1029/2007JD008481.

507

508 Garfinkel, C. I., and D. L. Hartmann, 2008: Different ENSO 509 teleconnections and their effects on the stratospheric polar 510 vortex. J. Geophys. Res., 113 , D18114,

511 doi:10.1029/2008JD009920.

512

513 Holton, J. R., and H.-C. Tan, 1980: The influence of the 514 equatorial quasi-biennial oscillation on the global circulation 515 at 50mb. J. Geophys. Res., 37, 2200-2208.

516

517 Hurwitz, M. M., P. A. Newman, F. Li, L. D. Oman, 0. Morgenstern, 518 P. Braesicke, and J. A. Pyle, 2010: Assessment of the Breakup of 519 the Antarctic Polar Vortex in Two New Chemistry-Climate Models. 520 J. Geophys. Res., 115, D07105, doi:10.1029/2009JD012788.

522 Juillet-Leclerc, A., S. Thiria, P. Naveau, T. Delcroix, N. Le 523 BeC, D. Blamart, and T. Corrège, 2006: SPCZ migration and ENSO 524 events during the 20th century as revealed by climate proxies 525 from a Fiji coral. Geophys. Res. Lett., 33, L17710, 526 doi:10.1029/2006GLO25950.

527

528 Kanamitsu, M., W. Ekisuzaki, J. Woollen, S.-K. Yang, J. J. Hnilo, 529 M. Fiorino, and G. L. Potter, 2002: NCEP-DOE AMIP-II Reanalysis $530 \quad(\mathrm{R}-2)$ Bull. Am. Meteorol. Soc., 83, 1631-1643, 531 do i : 10.1175/BAMS-83-11-1631(2002) $083<1631:$ NAR $>2.3$. C0;2. 
533 Kug, J.-S., F.-F. Jin, and S.-I. An, 2009: Two types of El Niño 534 events: cold tongue El Niño and warm pool El Niño. J. Climate, $53522,1499-1515$.

536

537 Larkin, N.K., and D. E. Harrison, 2005: On the definition of El 538 Niño and associated seasonal average U.S. Weather anomalies. 539 Geophys. Res. Lett., 32, L13705, doi:10.1029/2005GL022738.

540

541 Manzini, E., M. A. Giorgetta, M. Esch, L. Kornblueh, and E. 542 Roeckner, 2006: The influence of sea surface temperatures on the 543 Northern winter stratosphere: ensemble simulations with the 544 MAECHAM5 model. J. Climate, 19, 3863-3881.

545

546 Newman, P. A., E. R. Nash, and J. E. Rosenfield, 2001: What 547 controls the temperature of the Arctic stratosphere during the 548 spring? J. Geophys. Res., 106, D17, 19,999-20,010.

550 Randel, W. J., R. R. García, N. Calvo, and D. Marsh, 2009: ENSO 551 influence on zonal mean temperature and ozone in the tropical 552 lower stratosphere. Geophys. Res. Lett., 36, L15822, 553 doi:10.1029/2009GL039343.

555 Rasmusson, E. M., and T. H. Carpenter, 1982: Variation in 556 tropical sea surface temperature and surface wind fields 557 associated with Southern Oscillation/El Niño. Mon. Weather Rev., 558 110, 354-384.

560 Sassi, F., D. Kinnison, B. A. Boville, R. R. Garcia, and R. 561 Roble, 2004: Effect of El Niño-Southern Oscillation on the 562 dynamical, thermal, and chemical structure of the middle 
563 atmosphere. J. Geophys. Res., 94, 14705-14716, 564 doi:10.1029/JD094iD12p14705.

566 Taguchi, M., 2010: Wave driving in the tropical lower 567 stratosphere as simulated by WACCM. Part II: ENSO-induced 568 changes for northern winter. J. Atm. Sci., 67 , 569 doi:10.1175/2009JAS3144.1.

571 Uppala, S. M., and Coauthors, 2005: The ERA-40 re-analysis. $Q$. 572 J. R. Meteorol. Soc., 131, 2961-3012, doi:10.1256/qj.04.176.

574 Vera, C., G. Silvestri, V. Barros, and A. Carril, 2004: 575 Differences in El Niño response over the Southern Hemisphere. $J$. 576 Climate, 17, 1741-1753.

578 Xie, S.-P., C. Deser, G. A. Vecchi, J. Ma, H. Y. Teng, and A. T. 579 Wittenberg, 2010: Global warming pattern formation: sea surface 580 temperature and rainfall. J. Climate, 23, 966-986.

582 Yeh, S.-W., B. Y. Yim, Y. Noh, and B. Dewitte, 2009: Changes in 583 mixed layer depth under climate change projections in two CGCMs. 584 Climate Dynamics, 33, 199-213.

586 Yu, J.-Y. and S. T. Kim, 2010: Three evolution patterns of 587 Central-Pacific El Niño. Geophys. Res. Lett., 37 , L08706, 588 doi:1029/2010GLO42810. 
Tables \& Figures

590

\begin{tabular}{|c|llllllllllllll|}
\hline WPEN & 1986 & $\begin{array}{l}1991 \\
*\end{array}$ & $\begin{array}{l}1994 \\
*\end{array}$ & 2002 & $\begin{array}{l}2003 \\
*\end{array}$ & 2004 & 2006 & 2009 & & & & & & \\
\hline CTEN & 1982 & 1987 & 1997 & & & & & & & & & \\
\hline ENSON & 1979 & 1980 & 1981 & 1985 & 1989 & 1992 & 1993 & 1996 & 2000 & 2001 & 2005 & 2008 \\
& $*$ & & $*$ & & $*$ & & & $*$ & $*$ & $*$ & $*$ & \\
\hline
\end{tabular}

Table 1: Years classified as WP El Niño (WPEN), CT El Niño 593 SON mean Niño 3 and Niño 4 indices, as described in the text. 594 Events marked with a star symbol coincide with years when the QBO 595 is in its easterly phase.

596

\begin{tabular}{|c|c|c|c|c|c|}
\cline { 2 - 6 } \multicolumn{1}{c|}{} & ERA-40 & \multicolumn{2}{c|}{ MERRA } & \multicolumn{2}{c|}{ NCEP } \\
\cline { 2 - 6 } \multicolumn{1}{c|}{} & $1979-2001$ & $1979-2001$ & $1979-2009$ & $1979-2001$ & $1979-2009$ \\
\hline WPEN & $16.55 \pm$ & $15.77 \pm$ & $12.47 \pm$ & $14.54 \pm$ & $11.58 \pm$ \\
& 6.18 & 8.02 & 7.74 & 6.76 & 7.06 \\
\hline CTEN & $11.41 \pm$ & $11.36 \pm$ & $11.36 \pm$ & $9.93 \pm 2.88$ & $9.93 \pm 2.88$ \\
& 3.44 & 3.48 & 3.48 & & \\
\hline ENSON & $12.22 \pm$ & $11.73 \pm$ & $11.72 \pm$ & $10.82 \pm$ & $10.78 \pm$ \\
& 5.18 & 4.12 & 3.94 & 4.52 & 4.24 \\
\hline
\end{tabular}

Table 2: October/November mean eddy heat flux (K $\left.\mathrm{m} \mathrm{s}^{-1}\right)$ at 40 $59880^{\circ} \mathrm{S}, 100 \mathrm{hPa} \pm 2$ standard deviations for the WP El Niño, CT El 599 Niño and ENSO neutral cases. Years shown in the second row 600 denote SON seasons.

601

\begin{tabular}{|c|c|c|c|c|}
\cline { 3 - 5 } \multicolumn{2}{c|}{} & ERA-40 & MERRA & NCEP \\
\hline \multirow{3}{*}{ WPEN } & QBO-E & $18.28 \pm 2.06$ & $16.64 \pm 5.10$ & $15.26 \pm 4.34$ \\
\cline { 2 - 5 } & $\begin{array}{l}\text { QBO-W \& } \\
\text { neutral }\end{array}$ & 13.08 & $9.97 \pm 2.94$ & $8.90 \pm 2.58$ \\
\hline \multirow{2}{*}{ ENSON } & QBO-E & $11.90 \pm 6.78$ & $11.73 \pm 5.06$ & $10.62 \pm 5.72$ \\
\cline { 2 - 5 } & $\begin{array}{c}\text { QBO-W \& } \\
\text { neutral }\end{array}$ & $12.68 \pm 1.28$ & $11.71 \pm 2.08$ & $11.00 \pm 2.58$ \\
\hline
\end{tabular}


602 Table 3: October/November mean eddy heat flux $\left(\mathrm{K} \mathrm{m} \mathrm{s}^{-1}\right)$ at 40 $60380^{\circ} \mathrm{S}, 100 \mathrm{hPa} \pm 2$ standard deviations for the WP El Niño and ENSO 604 neutral cases. Eddy heat flux is shown as a function of both 605 ENSO and QBO phase.

606

607 

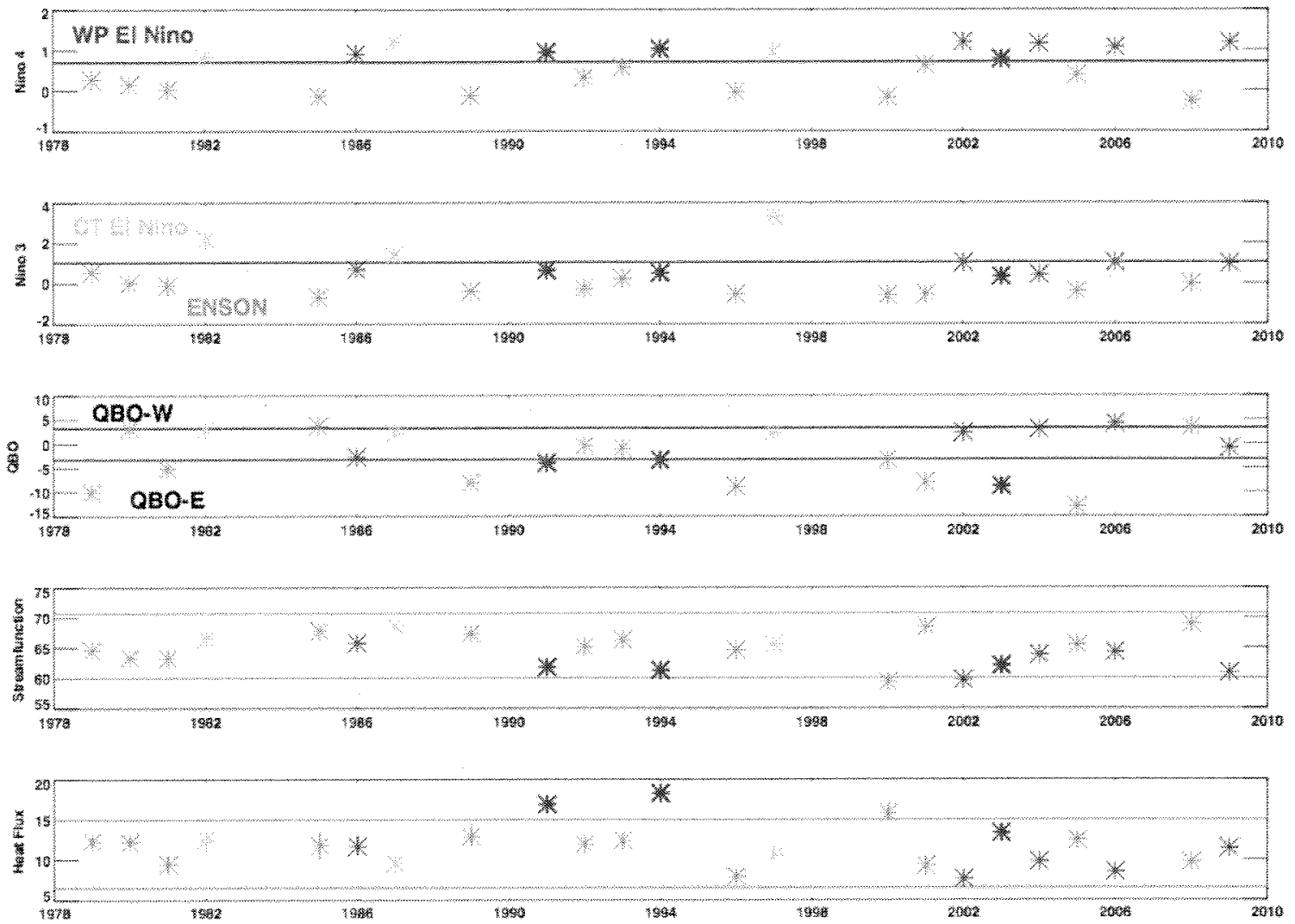

608 Figure 1: Timeseries showing conditions during $\mathrm{El} N \mathrm{~N}$ ño and 609 ENSO neutral events within the $1979-2009$ period. Thick (thin) 610 blue stars indicate WP El Nino events coincident with the 611 easterly (westerly or neutral) phase of the QBO. Green stars 612 indicate CT El Niño events. Brown stars indicate ENSO neutral 613 events. The top row shows the SON Niño 3 index (as described in 614 the text); the black line shows the cutoff value defining CT El 615 Niño events. The second row shows the SON Niño 4 index; the 616 black line shows the cutoff value defining WP El Niño events. 617 The third row shows the QBO index (as described in the text); 618 black lines show the cutoff values defining easterly QBO and 619 westerly QBO events. The fourth row shows the average SON

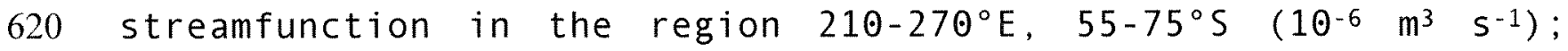
621 brown lines indicate \pm 2 standard deviations from the mean of 622 ENSO neutral events. The fifth row shows October/November eddy 
623 heat flux $\left(\mathrm{K} \mathrm{m} \mathrm{s}^{-1}\right)$ at $100 \mathrm{hPa}, 40-80^{\circ} \mathrm{S}$; brown lines indicate \pm 2 624 standard deviations from the mean of ENSO neutral events.

(a) WP El Nino-ENSON

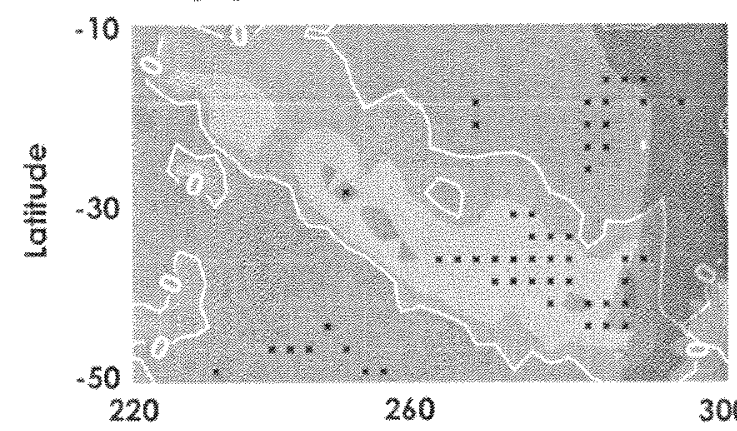

(b) CT EI Nino-ENSON

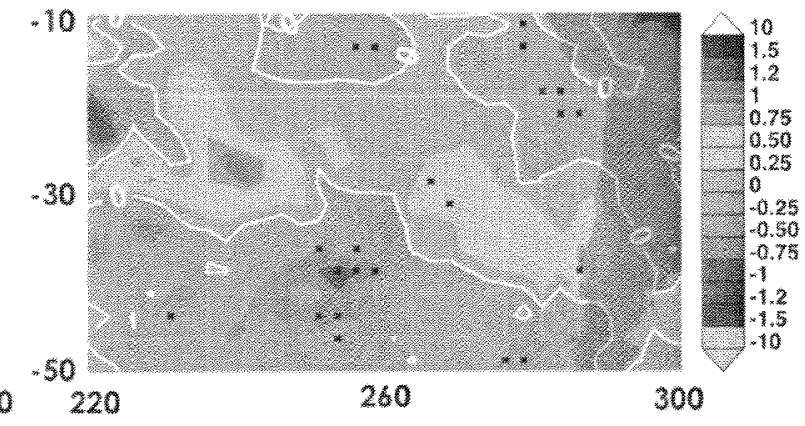

Longinude

625

626 Figure 2: GPCP SON precipitation differences ( $m m$ day-1) from a 627 composite of ENSO neutral events, in (a) WP El Niño events and 628 (b) CT El Niño events, in the SPCZ region. White contours 629 indicate zero difference from the composite of ENSO neutral 630 events. Black $X s$ indicate differences that are significant at 631 the $95 \%$ confidence level. 
M. M. Hurwitz et al. (2010)

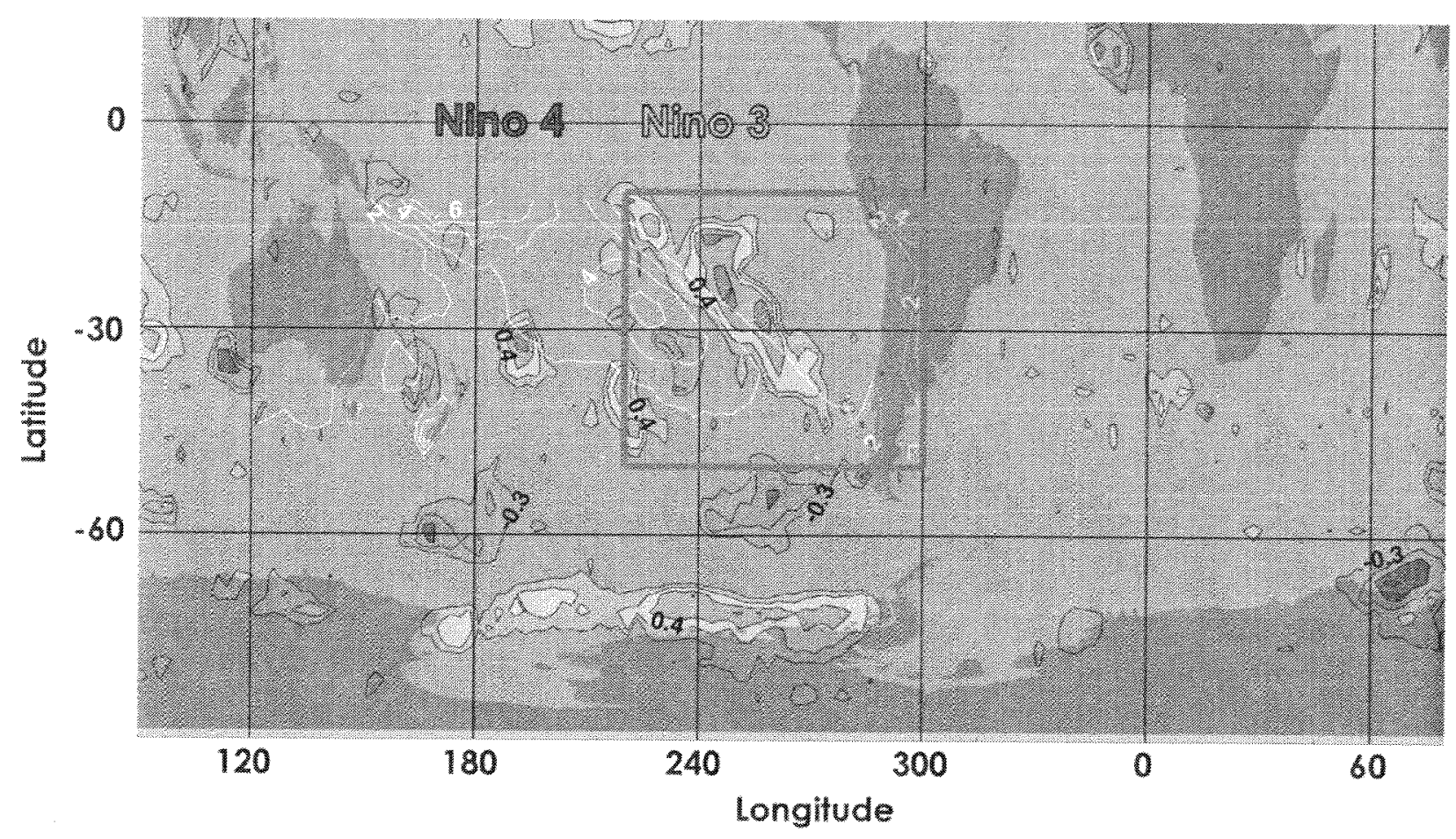

632

Figure 3: Filled contours show the point correlation between 634 GPCP SON precipitation and NCEP October/November eddy heat flux 635 at $100 \mathrm{hPa}, 40-80^{\circ} \mathrm{S}$, for the $1979-2007$ period. The highest 636 correlation coefficient is 0.69 . The SPCZ region, highlighted in 637 Figure 2, is shown as the red box. White contours show 638 Climatological mean SON precipitation $(\mathrm{mm}$ day-1) in the South 639 Pacific. The locations of the Niño 3 and Niño 4 regions are 640 labeled. 
M. M. Hurwitz et al. (2010)

in the Antarctic Stratosphere
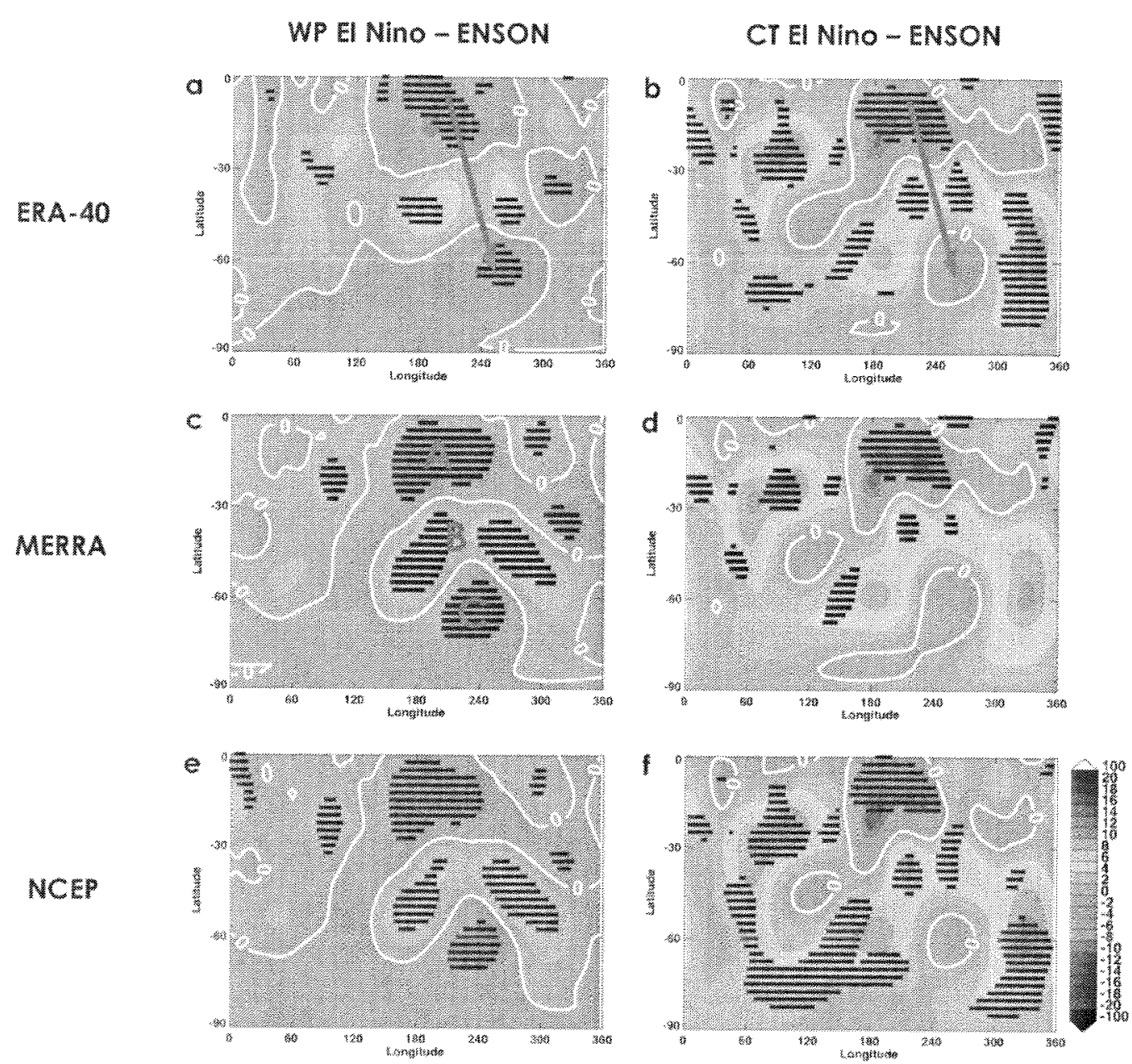

641

642 Figure 4: Longitude-latitude contour plots showing SON mean $643250 \mathrm{hPa}$ streamfunction differences $\left(10^{-6} \mathrm{~m}^{3} \mathrm{~s}^{-1}\right)$, from a composite 644 of ENSO neutral events, in WP El Niño events ( $a, c$, e) and CT El 645 Niño events (b, $d, f)$. White contours indicate zero difference 646 from the composite of ENSO neutral events. Black Xs indicate 647 differences that are significant at the $95 \%$ confidence level. 648 Red arrows ( $a$, b) indicate the approximate direction of the 649 planetary wave trains induced by $E l$ Niño events. Red letters $A$, $650 \mathrm{~B}$ and $C$ (c) indicate the three regions discussed in the text. 

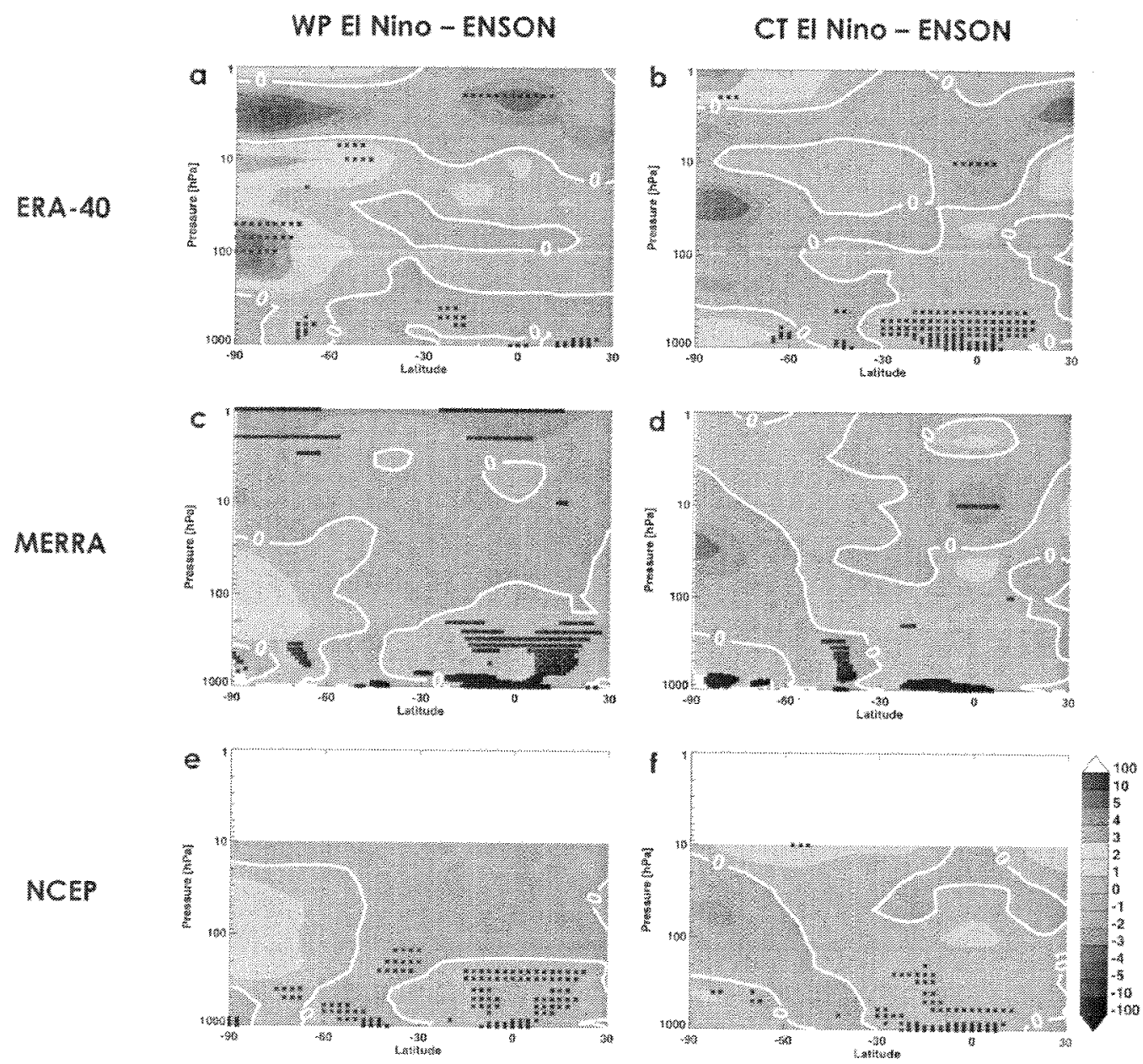

651

652 Figure 5: Latitude-height cross-sections of November/December 653 mean temperature differences (K), from a composite of ENSO 654 neutral events, in WP El Niño events (a, c, e) and CT El Niño 655 events (b, d, f). White contours indicate zero difference from 656 the composite of ENSO neutral events. Black Xs indicate 657 differences that are significant at the $95 \%$ confidence level. 658 

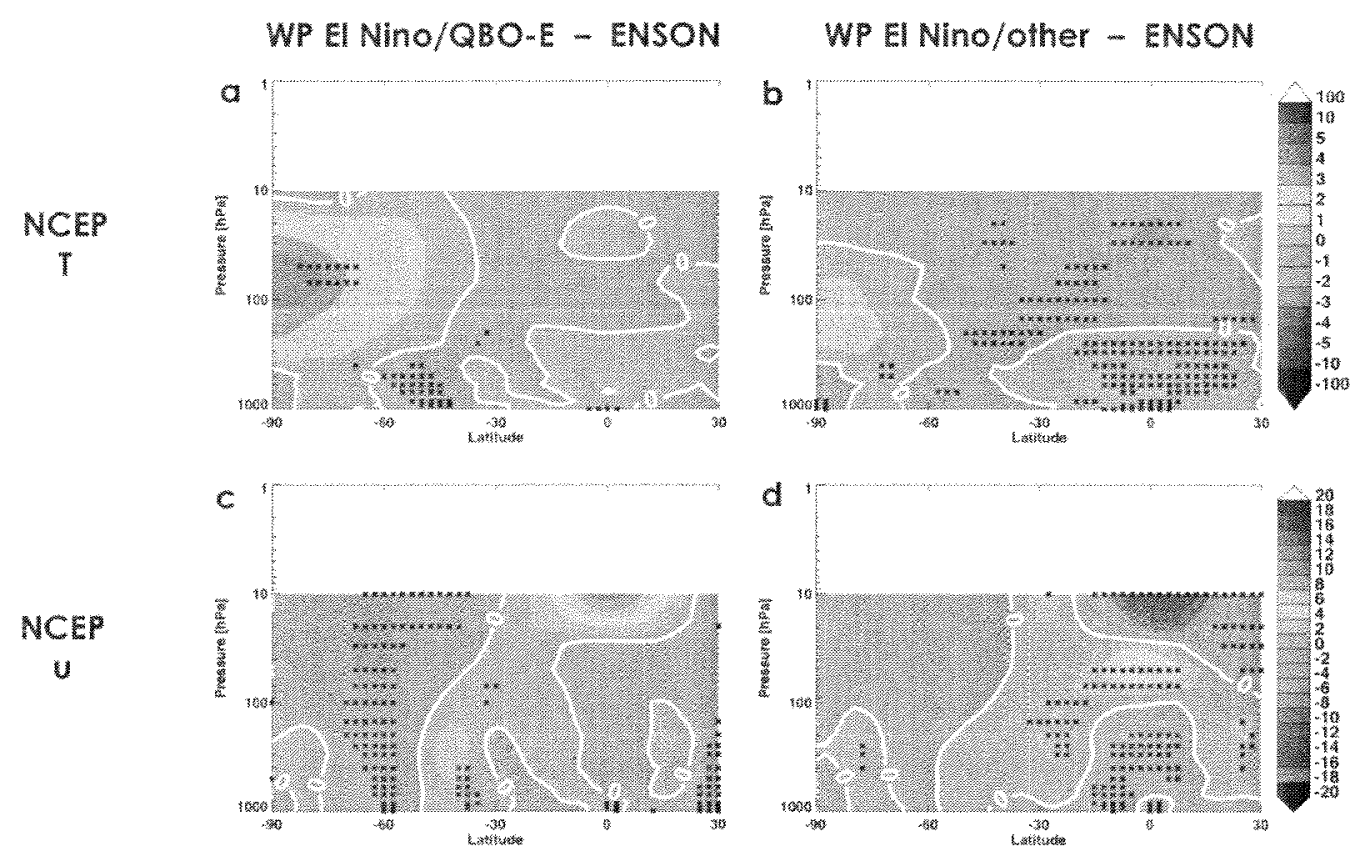

658

659 Figure 6: Latitude-height cross-section of November/December 660 mean temperature differences (K) ( $a, b)$ and zonal wind 661 differences $\left(\mathrm{m} \mathrm{s}^{-1}\right)$ ( $\left.c, \mathrm{~d}\right)$, from a composite of ENSO neutral 662 events, in WP El Niño events with easterly QBO (a, c) and WP El 663 Niño events with neutral or westerly QBO (b, d). The NCEP 664 reanalysis is shown. White contours indicate zero difference 665 from the composite of ENSO neutral events. Black Xs indicate 666 differences that are significant at the $95 \%$ confidence level. 